\title{
SAFETY PHILOSOPHY AS A METHODOLOGICAL BASIS OF PEDAGOGICAL PROBLEM- SOLVING OF LIFE SAFETY
}

\section{Костенок Павел Иванович}

Профессор кафедры безопасности

жизнедеятельности, Уральский государственный университет физической культуры, доктор педагогических наук, профессор

E-mail: kp1967@mail.ru

\section{Коняхина Галина Петровна}

Доцент кафедры теории и методики физической культуры и спорта, Южно-Уральский государственный гуманитарно-педагогический университет

E-mail: eaglez@mail.ru

Аннотация. В статье рассматриваются положения философии безопасности в аспекте ее значимости для педагогического решения проблем безопасности жизнедеятельности. Раскрывается сущность парадигм защищенности

\section{Kostenok Pavel I.}

Professor at the Department of Life Safety, Ural State University of Physical Culture, ScD in Education, Full Professor

E-mail:kp1967@mail.ru

\section{Konyahina Galina P.}

Assistant Professor at the Department of Theory and Methods of Physical Training and Sports, South Ural State Humanitarian Pedagogical University

E-mail: eaglez@mail.ru

Abstract. The article deals with theses of safety philosophy in terms of its significance for the pedagogical problem-solving of life safety. It reveals the content of security and development paradigms, makes a comparative

(с) Костенок П. И., Коняхина Г. П., 2020 
и развития, проводится сравнительный анализ опыта и возможностей их реализации как методологических оснований педагогики безопасности, выявляется и обосновывается специфика этой реализации. Авторами также утверждается необходимость методологического перехода от парадигмы защищенности к парадигме развития.

Ключевые слова: безопасность, опасность, безопасность жизнедеятельности, философия безопасности, парадигма защищенности, парадигма развития, методологическое основание, педагогическая наука, образовательная деятельность. analysis of experience and possibilities of their implementation as a methodological basis of safety education, identifies and proves the specificity of this implementation. The authors also state the need of methodological conversion from the security paradigm to the development paradigm.

\section{Keywords: safety, danger, life safety, safety philosophy, security paradigm, development paradigm, methodological basis, education science, educational activity.}

В современной науке понятие «методология» трактуется двояко: с одной стороны, как система методов, применяемых в той или иной сфере человеческой деятельности, а с другой - как учение (теория) о данной системе. При этом метод в самом широком своем значении понимается как способ деятельности субъекта в любой ее форме. Методы исследования в педагогике - «приемы, процедуры и операции эмпирического и теоретического познания и изучения явлений действительности. Система методов исследования определяется исходной концепцией исследователя, его представлениями о сущности и структуре изучаемого, общей методологической ориентации, целей и задач конкретного исследования» [1, с. 570].

В структуре методологии педагогического исследования, как правило, выделяют философский, общенаучный, конкретно-научный и частно-научный (технологический) уровни. Философский уровень методологии предполагает выделение исходных философских идей и ключевых понятий, на базе которых развивается педагогика как наука. Кроме того, уже само обращение к философскому аспекту того или иного феномена требует его анализа с онтологических, гносеологических, аксиологических, праксеологических и наконец методологических позиций.

Целью настоящей статьи является анализ и обоснование положений философии безопасности как методологических оснований педагогического решения крайне актуальных в настоящее время проблем безопасности жизнедеятельности.

Философия безопасности - относительно новая отрасль науки. Об этом свидетельствует уже тот факт, что еще сравнительно недавно, в 2001 г., по утверждению В. С. Поликарпова, в философских словарях отсутствовали толкования ее ключевых понятий «опасность» и «безопасность» [2]. В настоящее время ситуация кардинально не изменилась. Простейший интернет-запрос в «Словарях и энциклопедиях на Академике» предоставляет толкование данных понятий в справочных изданиях, посвященных проблемам 
различных наук и сфер деятельности (русского языка, техники безопасности, строительства, экологии, гражданской защиты, экономики, военного дела), но только не философии.

В научном литературном пространстве рассматриваемая отрасль философии представлена трудами отечественных и зарубежных ученых: У. Бека, 3. З. Биктимировой, В. С. Диева, Э. Гидденса, Э. П. Литвинова, Н. Лумана, А. Ю. Моздакова, В. С. Поликарпова, А. А. Прохожева, Н. Н. Рыбалкина, С. Н. Соколовой, В. С. Хомяковой, Р. Г. Яновского и др. Анализ данных трудов позволяет выделить две методологические парадигмы, используемые исследователями при разработке теорий, концепций и систем безопасности, а именно: парадигму защищенности и парадигму развития. Первая является определяющей при разработке нормативно-правовых документов и организации социальной практики по обеспечению безопасности личности, общества, государства и окружающей среды.

В рамках парадигмы защищенности в дихотомии понятий «опасность» и «безопасность» ключевым является понятие «опасность», в самом обобщенном виде трактуемое как условия (свойство, следствие деятельности людей, факт, фактор, ситуация, процесс, объект, источник), характеризуемые угрозой (негативным потенциальным или реальным воздействием, поражением людей, вредом здоровью, разрушением и гибелью системы, гибелью людей, разрушающим действием).

Соответственно, безопасность понимается как условия (отсутствие потенциальной или реализованной опасности, система мер защиты, состояние, фактор), при которых опасность не угрожает, существуют определенные меры защиты человека или системы, риск для здоровья и безопасности находится на приемлемом уровне. При этом наиболее востребованным оказывается определение безопасности как «состояния защищенности личности, общества, государства и среды жизнедеятельности от внутренних и внешних угроз или опасностей» [3]. В указанном контексте безопасность:

- «выступает интегральной формой выражения жизнестойкости и жизнеспособности объектов биосферы и ноосферы...» [3], определяемых их природой;

- предполагает идентификацию, профилактику и ликвидацию последствий проявления опасностей.

Критерием и показателем безопасности рассматривается риск, трактуемый как: «1) вероятностная мера опасности или совокупности опасностей, установленная для определенного объекта в виде возможных потерь за заданное время; 2) осознанная опасность (угроза) наступления в любой системе негативного события с определенными во времени и пространстве последствиями» [4]. Риск присутствует всегда и повсеместно, о чем гласит аксиома о потенциальной опасности деятельности. А современное общество все более становится обществом риска [5].

Подобное понимание безопасности базируется на выделении природной способности различных систем посредством саморегуляции сохранять устойчивость (качество) при воздействии на них отрицательных условий (факторов, ситуаций, источников). Но в данном случае речь идет о замкнутых системах, способных к поддержанию гомеостаза, но отрицающих развитие [6].

Трактовка безопасности как защищенности требует определения понятия «защищенность», которое трактуется, в свою очередь, как с точки зрения процесса обеспечения безопасности, так и с точки зрения его результата [7]. 
В научных и нормативно-правовых источниках общеупотребительным стало и само название новой интегративной науки о безопасности - «безопасность жизнедеятельности». При этом понятие «жизнедеятельность» применительно к человеку, социальной группе или обществу в целом употребляется в расширительном толковании, отражающем его природную и социальную сущность. Аналогично в расширительном толковании зачастую употребляется понятие «среда обитания». Хотя более подходящим, на наш взгляд, является понятие «среда человека», активно используемое в социальной экологии [8].

В рамках рассматриваемой парадигмы формируется и такая наука, как ноксология учение о материальных опасностях и потенциальных угрозах, возникающих в системе взаимодействия человека и окружающей среды. Она разрабатывается, прежде всего, применительно к техносфере, а ее понятийный аппарат представлен понятиями, связанными с опасностями, опасными событиями, поражением и риском [9]. Ноксология обосновывает классификации опасностей и угроз, наиболее известной из которых является классификация по природе их происхождения. Выделяются также различные виды безопасности.

В качестве варианта применения парадигмы защищенности мы склонны рассматривать попытки ряда исследователей интерпретировать феномен «устойчивое развитие системы» как условие обеспечения ее безопасности. Так, О. Н. Климов в своей диссертации утверждает: «Все, что тормозит развитие, следует рассматривать как опасность» [10, с. 25]. Есть и другие точки зрения. Например, Н. Н. Моисеев считает понятия «устойчивость» и «развитие» взаимоисключающими и отмечает, что «...устойчивого развития просто может не быть - если есть развитие, то стабильности уже нет». Устойчивое развитие, по его мнению, есть «... развитие, допустимое или согласованное с состоянием Природы и его законами» [11].

В этом же контексте звучит и формулировка термина «устойчивое развитие» в глобальном масштабе, впервые прозвучавшем в докладе «Наше общее будущее» Всемирной комиссии ООН по окружающей среде и развитию [12]. Следует отметить, что теория устойчивого развития во многом перекликается с концепцией ноосферы В. И. Вернадского.

Вместе с тем сейчас во многих научных работах наблюдается либо отход от парадигмы защищенности как методологического основания исследования проблем безопасности, либо ее откровенная критика. Так, Н. Н. Рыбалкин [13] и С. Н. Соколова [14] отмечают появление альтернативных научных дефиниций безопасности, что связывается ими с осознанием уязвимости отождествления сущности рассматриваемого феномена с защищенностью. По мнению упомянутых авторов, эти дефиниции не безупречны, а критические замечания в их адрес можно свести к нижеследующему (табл. 1).

Не вписывающейся в каноны парадигмы защищенности представляется нам активно разрабатываемая и внедряемая в настоящее время в различные сферы социальной деятельности концепция культуры безопасности жизнедеятельности.

Первая попытка связать между собой понятия «культура» и «безопасность» была сделана в документах МАГАТЭ в конце 1980-х гг. С тех пор понятия «культура безопасности», «культура безопасности поведения», «культура безопасности жизнедеятельности» прочно вошли в научный оборот, а последнее - и в нормативно-правовые документы, затрагивающие вопросы подготовки населения к действиям в чрезвычайных ситуациях, а также обучения молодежи основам безопасности жизнедеятельности. 
Анализ научных дефиниций феномена «безопасность» (по: [14])

\begin{tabular}{|c|c|}
\hline $\begin{array}{c}\text { Сущность того или иного } \\
\text { определения безопасности }\end{array}$ & $\begin{array}{c}\text { Критические замечания, которые высказываются учеными } \\
\text { в адрес того или иного определения }\end{array}$ \\
\hline $\begin{array}{l}\text { Безопасность - отсутствие } \\
\text { опасностей }\end{array}$ & $\begin{array}{l}\text { 1) достичь абсолютной безопасности невозможно, о чем свидетельству- } \\
\text { ет аксиома о потенциальной опасности деятельности; } \\
\text { 2) безопасность без опасности не имеет смысла, она обретает свое суще- } \\
\text { ствование только с появлением угроз; } \\
\text { 3) данное понимание безопасности влечет за собой отрицание разви- } \\
\text { тия (совершенствования) и саморазвития (самосовершенствования), } \\
\text { которые с позиции репродукции системы может рассматриваться как } \\
\text { опасность или угроза }\end{array}$ \\
\hline $\begin{array}{l}\text { Безопасность - свойство (атри- } \\
\text { бут) системы }\end{array}$ & $\begin{array}{l}\text { Безопасность не может быть объективно присуща системе, она вторич- } \\
\text { на; свойства системы, обеспечивающие ее безопасность, необходимо } \\
\text { сформировать, они являются результатом некоей социальной деятель- } \\
\text { ности }\end{array}$ \\
\hline $\begin{array}{l}\text { Безопасность - специфиче- } \\
\text { ская деятельность (характерно } \\
\text { для доктринальных докумен- } \\
\text { тов и законодательных актов) }\end{array}$ & $\begin{array}{l}\text { В скрытом виде подобные дефиниции содержат понимание безопасно- } \\
\text { сти не как деятельности, а как цели }\end{array}$ \\
\hline $\begin{array}{l}\text { Безопасность - состояние (в } \\
\text { частности социума) }\end{array}$ & $\begin{array}{l}\text { Такое понимание безопасности ведет к отрицанию динамичного и } \\
\text { самостоятельного характера развития системы }\end{array}$ \\
\hline
\end{tabular}

Примечательно, что теоретических философских исследований, посвященных феномену культуры безопасности, относительно немного, в отличие от обилия соответствующих прикладных исследований [15]. Применительно к педагогическим наукам это подтверждается работой В. В. Гафнера [16].

Приведем несколько определений анализируемых понятий, обосновываемых в различных нефилософских источниках в разные годы:

- «культура безопасности - это способы разумной жизнедеятельности человека в области обеспечения безопасности; результаты этой жизнедеятельности и степень развитости личности и общества в этой области» [17, с. 71];

- «культура безопасности жизнедеятельности - уровень развития человека и общества, характеризуемый значимостью задачи обеспечения безопасности жизнедеятельности в системе личных и социальных ценностей, распространенностью стереотипов безопасного поведения в повседневной жизни и в условиях опасных и чрезвычайных ситуаций, степенью защищенности» [18, с. 88];

- «культура безопасности личности - совокупность норм, взглядов и установок, характеризующих отношение индивида к природе, личной, общественной и национальной безопасности [19, с. 62];

- культура безопасности жизнедеятельности - «состояние развития личности, которое характеризуется осознанным отношением к вопросам личной безопасности и безопасности окружающих, практической деятельностью по снижению социальных рисков, развитостью психологических и духовно-нравственных качеств, владением нормами безопасного и продуктивного поведения в социуме, ведением здорового образа жизни, развитостью умений пользоваться информацией» [20]; 
- культура безопасности жизнедеятельности - «составная часть общей культуры, характеризующая уровень подготовки в области безопасности жизнедеятельности и осознанную потребность в соблюдении норм и правил безопасного поведения» [21].

Данные определения показывают наличие общих оснований и предполагают, что «культура безопасности» есть феномен:

1) социальный, могущий существовать как на личностном, так и на общественном уровне;

2) системный, имеющий неоднородную структуру и сам являющийся частью общей культуры;

3) развивающийся, предполагающий направленный закономерный переход от одного своего внутреннего качества к другому.

Как и культура в целом, рассматриваемый феномен предполагает наличие некоего социально значимого результата своего развития в виде знаний, умений, навыков, личностных качеств, норм поведения, подлежащего передаче от поколения к поколению.

Высказанные идеи вполне соотносятся с философским определением культуры безопасности, сформулированным Ю. В. Фетисовой. По ее мнению, исследуемый феномен представляет собой «динамическую по содержанию (дает представление о пространственно-временной контекстуальности), но относительно стабильную по структуре (выявляет семиотическую структурированность) систему репрезентаций культурных смыслов концепта «безопасность», результирующую в общественной практике, которая эволюционирует вместе с этой системой (описывает деятельностное воплощение)» [15, с. 13].

По мнению ряда авторов (Э. П. Литвинов, А. А. Прохожев, Н. Н. Рыбалкин, С. Н. Соколова и др.), применение методологической парадигмы развития в исследовании проблем обеспечения безопасности оказывается более целесообразным и продуктивным.

В частности, доказывая целесообразность обращения к феномену «развитие», Н. Н. Рыбалкин отмечает, что «существование естественной системы имеет не статический, а динамический характер. Система не только функционирует, воспроизводя свои системные связи, но и развивается... а всякое естественное изменение в той или иной мере отрицает существующее состояние. Поскольку развитие естественных систем имеет объективный характер, детерминируемый природой системы, отрицание того или иного состояния системы не означает отрицания ее существования как системы. Наоборот, она сохраняется в этом изменении (отрицании)... Сохранение же некоторого состояния в ущерб развивающемуся естеству приводит к отрицанию природы, а значит, и самой системы. Вследствие этого в объективном смысле безопасность естественной системы определяется не сохранением ее существующего состояния, а сохранением ее природы. Поэтому опасность для системы представляет не отрицание существующего, а отрицание ее природы. .» [13, с. 44-45].

Вместе с тем он указывает и на недопустимость изучения социального бытия лишь с позиции сохранения природной определенности естественных систем. Любое разрушение последних человеком возможно, но лишь при обязательном понимании и скрупулезном просчитывании им последствий своих действий.

В отличие от парадигмы защищенности, предполагающей отрицание опасностей и последующее самоутверждение системы, парадигма развития во главу угла ставит 
самоутверждение, а отрицание опасностей в данном случае рассматривается лишь как условие последнего. Если в рамках парадигмы защищенности происходит отождествление безопасности с жизнедеятельностью, а соответственно - определение идеи безопасности в качестве ключевой социальной идеи, то в рамках парадигмы развития внимание системы акцентируется на развитии ее собственных внутренних сил. В данном случае «деятельность как фактор развития направлена не на “защищенность” интересов, а на их реализацию» [13, с. 49].

Подобный подход, помимо всего прочего, позволяет избежать чрезмерного преувеличения потребности личности и общества в безопасности, имеющего место в ряде исследований (В. А. Девисилов, Л. А. Михайлов, В. В. Сапронов, Л. И. Шершнев и др.) и критиковавшегося нами ранее [8; 22].

Мнение Н. Н. Рыбалкина о первичности развития и вторичности безопасности разделяет А. А. Прохожев, считающий, что «безопасность призвана обеспечить развитие...». При этом «вторичность безопасности ничуть не умаляет ее роли и значения в объективной действительности... без обеспечения безопасности всякая человеческая деятельность оказывается бесцельной...» [23, с. 10-11]. Ученый также отмечает сложный диалектический характер взаимосвязи между развитием и безопасностью, обусловливаемый невозможностью разделения этих двух важнейших функций жизнедеятельности.

Э. П. Литвинов в числе критериев безопасности сложных социальных систем выделяет не только целостность и степень эффективности функционирования последних, но и степень их устойчивого динамичного развития. Достижение соответствующих показателей безопасности, по его мнению, возможно посредством реализации «закона диалектического соответствия направленности и содержания субъективных факторов системы безопасности объективным условиям ее целостного существования, динамичного развития и эффективного функционирования» [24].

Обращение к раскрываемым выше парадигмам защищенности и развития как к методологическим основаниям педагогического решения проблем обеспечения безопасности жизнедеятельности предопределяет специфику их реализации в педагогической науке и практике образования (табл. 2).

В частности, формирование мотивации к образованию в рамках парадигмы развития должно осуществляться, на наш взгляд, на основе понимания в качестве ключевого мотива личности ее потребности в саморазвитии. В итоге - преодоление «зацикленности» на обеспечении (личностью. - К. П.) своей безопасности, не позволяющей реализовываться другим потребностям, то есть потребностям высшего порядка» [25, с. 126]. При этом потребность в безопасности из комплекса мотивов учебной деятельности не исключается.

Соответственно, будет происходить трансформация цели и задач образовательной деятельности: на первый план выйдут задачи воспитания и развития, а не обучения. В числе важнейших из них - воспитание социального оптимизма и ответственности как социально значимых качеств, а также развитие личностного и профессионального мировоззрения обучаемых. Нацеленность образовательного процесса в сфере безопасности жизнедеятельности на воспитание социального оптимизма и ответственности, как указывалось нами ранее:

- «во-первых, позволит предотвратить возможное появление у обучаемых тревожности и различного рода страхов; 
Специфика реализации парадигмы защищенности и парадигмы развития как методологических оснований педагогического решения проблем обеспечения безопасности жизнедеятельности

\begin{tabular}{|c|c|}
\hline $\begin{array}{c}\text { Особенности реализации парадигмы } \\
\text { защищенности }\end{array}$ & Особенности реализации парадигмы развития \\
\hline \multicolumn{2}{|c|}{ Особенности реализации мотивационно-целевого компонента образовательной деятельности } \\
\hline $\begin{array}{l}\text { • формирование мотивации к образованию } \\
\text { на основе понимания в качестве ключевого мотива } \\
\text { личности ее потребности в безопасности; } \\
\text { • цель образовательной деятельности - формиро- } \\
\text { вание у обучающихся знаний, умений, навыков, } \\
\text { личностных качеств и норм поведения, обуслов- } \\
\text { ливающих их готовность к обеспечению безопас- } \\
\text { ности себя и окружающих в повседневной жизни, } \\
\text { последующей профессиональной деятельности и в } \\
\text { условиях чрезвычайных ситуаций; } \\
\text { • при определении задач образовательной дея- } \\
\text { тельности акцент делается на обучающую задачу }\end{array}$ & $\begin{array}{l}\text { • формирование мотивации к образованию } \\
\text { на основе понимания в качестве ключевого мотива } \\
\text { личности ее потребности в саморазвитии (самораз- } \\
\text { витии); } \\
\text { • цель образовательной деятельности - формиро- } \\
\text { вание у обучающихся знаний, умений, навыков, } \\
\text { личностных качеств и норм поведения, обуслов- } \\
\text { ливающих их готовность к личностному и/или } \\
\text { профессиональному развитию (саморазвитию) } \\
\text { в различных условиях (в том числе в условиях, угро- } \\
\text { жающих безопасности их жизни и деятельности); } \\
\text { • при определении задач образовательной дея- } \\
\text { тельности акцент делается на воспитательную и } \\
\text { развивающую задачи }\end{array}$ \\
\hline \multicolumn{2}{|c|}{ Содержание образования } \\
\hline $\begin{array}{l}\text { структурировано в соответствии с решением } \\
\text { комплекса задач науки о безопасности жизнедея- } \\
\text { тельности: } \\
\text { • изучение и анализ различного рода опасностей; } \\
\text { • освоение принципов, методов, форм и средств } \\
\text { профилактики (предупреждения) опасностей; } \\
\text { • освоение принципов, методов, форм и средств } \\
\text { ликвидации последствий остаточного риска }\end{array}$ & $\begin{array}{l}\text { структурировано в соответствии с решением изме- } \\
\text { ненного (расширенного) комплекса задач науки о } \\
\text { безопасности жизнедеятельности: } \\
\text { • освоение принципов, методов, форм и средств } \\
\text { саморазвития личности; } \\
\text { • изучение и анализ различного рода опасностей; } \\
\text { - освоение принципов, методов, форм и средств } \\
\text { профилактики (предупреждения) опасностей; } \\
\text { - освоение принципов, методов, форм и средств } \\
\text { ликвидации последствий остаточного риска }\end{array}$ \\
\hline \multicolumn{2}{|c|}{ Организация образовательной деятельности } \\
\hline $\begin{array}{l}\text { осуществляется в основном в соответствии с прин- } \\
\text { ципами объяснительно-иллюстративного вида } \\
\text { обучения }\end{array}$ & $\begin{array}{l}\text { осуществляется в основном в соответствии с прин- } \\
\text { ципами развивающего и проблемного видов } \\
\text { обучения }\end{array}$ \\
\hline \multicolumn{2}{|c|}{ Контроль результатов образования } \\
\hline $\begin{array}{l}\text { • осуществляется в большей мере со стороны } \\
\text { обучающего; } \\
\text { • проверяются и оцениваются, как правило, конеч- } \\
\text { ные результаты образовательной деятельности }\end{array}$ & $\begin{array}{l}\text { • предполагает активное применение методов, } \\
\text { форм и средств самоконтроля и взаимоконтроля; } \\
\text { • требует не просто проверки и оценивания ко- } \\
\text { нечных результатов образовательной деятельнос- } \\
\text { ти, а оценивания (самооценивания) их динамики, } \\
\text { полученной в ходе мониторинга; } \\
\text { • особое значение приобретает самокорректиров- } \\
\text { ка образовательного процесса }\end{array}$ \\
\hline
\end{tabular}

- во-вторых, будет способствовать формированию у них осознанной ценностной избирательности в отношениях с окружающим миром;

- в-третьих, в определенной мере обеспечит их морально-психологическую подготовку к осуществлению социально ориентированной и сознательно регулируемой преобразовательной деятельности» [8, с. 140]. 
По нашему мнению, парадигма развития как методологическое основание предполагает также расширение триединой задачи науки о безопасности жизнедеятельности (идентификация опасностей - профилактика (предупреждение) опасностей - ликвидация последствий остаточного риска). Развитие любой системы в аспекте принятой методологии может рассматриваться как общая профилактика (предупреждение) опасностей, которая направлена на укрепление сущностных сил системы в целом безотносительно конкретной опасности. Принимая данное допущение, порядок решения задач науки о безопасности жизнедеятельности можно определить следующим образом:

- общая (первичная) профилактика (предупреждение) опасностей;

- идентификация опасностей;

- целевая (вторичная) профилактика (предупреждение) опасностей;

- ликвидация последствий остаточного риска.

По аналогии с медицинской профилактикой мы считаем допустимым говорить и о третичной профилактике, осуществляемой параллельно с решением последней задачи.

Сказанное обусловливает изменение структуры содержания образования, а также предопределяет специфику организации образовательной деятельности и контроля ее результатов.

Например, особое значение приобретают: принципы развивающего и проблемного обучения; методы, формы и средства самоконтроля и взаимоконтроля; мониторинг результатов образовательной деятельности и оценивание их динамики; самокорректировка образовательного процесса со стороны обучаемых.

Таким образом, анализ положений философии безопасности позволяет выделить две методологические парадигмы, применяемые при разработке проблем обеспечения безопасности жизнедеятельности: парадигму защищенности и парадигму развития. Каждая из них, реализованная в рамках педагогической науки и практике образования, имеет свои особенности. При этом необходим переход от парадигмы защищенности к парадигме развития.

\section{Список литературы}

1. Российская педагогическая энциклопедия: в 2 т. / гл. ред. В. В. Давыдов. М.: Большая российская энциклопедия, 1993. Т. 1: А-М. 608 с.

2. Поликарпов В. С. Философия безопасности: эссе. СПб. - Ростов н/Д. - Таганрог, 2001.

3. Безопасность. Термины МЧС // МЧС России. URL: http://www.mchs.gov.ru/dop/ terms/item/88452/ (дата обращения: 25.06.2019).

4. Риск. Термины МЧС // МЧС России. URL: http://www.mchs.gov.ru/dop/terms/ item/453796/ (дата обращения: 25.06.2019).

5. Бек У. Общество риска: на пути к другому модерну / пер. с нем. В. Седельника, Н. Федоровой. М.: Прогресс-Традиция, 2000. 383 с.

6. Губанов В. М., Капшунова И. К. Философская интерпретация безопасности жизнедеятельности // Педагогика высшей школы. 2016. № 3.1. C. 62-68. URL: https:// moluch.ru/th/3/archive/43/1446/ (дата обращения: 25.06.2019). 
7. Нестеров С. В. Безопасность как философско-правовая категория // Юридическая наука. 2013. № 1. С. 11-13.

8. Костенок П. И. Преподавание учебной дисциплины «Безопасность жизнедеятельности» в гуманитарном вузе: реальные диссонансы и потенциальный коллапс // Мир науки, культуры, образования. 2016. № 1(56). С. 136-145.

9. Ефремов С. В., Ковшов С. В., Зинченко А. В. Ноксология: учеб. пособие / под ред. С. В. Ефремова. СПб.: Изд-во политехн. ун-та, 2012. 250 с.

10. Климов О. Н. Национальная безопасность России в условиях глобализации (политологический аспект): дис. ... канд. полит. наук. М., 2003. 170 с.

11. Моисеев Н. Н. Судьба цивилизации. Путь разума. М.: Изд-во МНПУ, 1998. 228 с.

12. Наше общее будущее: доклад Международной комиссии по окружающей среде и развитию (МКОСР) / пер. с англ. под ред. С. А. Евтеева и P. А. Перелета. URL: http:// устойчивоеразвитие.pф/files/monographs/OurCommonFuture-introduction.pdf (дата обращения: 29.06.2019).

13. Рыбалкин Н. Н. Природа безопасности // Вестн. Московского ун-та. Сер. 7: Философия. 2003. № 5. С. 36-52.

14. Соколова С. Н. Феноменология безопасности современного общества: моногр. Пинск: ПолесГУ, 2013. 183 с.

15. Фетисова Ю. В. Культура безопасности: автореф. дис. ... канд. филос. наук. Омск, 2009. $21 \mathrm{c}$.

16. Гафнер В. В. Культура безопасности: аналитический обзор диссертационных исследований (педагогические науки, 2002-2012 гг.). Екатеринбург, 2013. 200 с.

17. Власова Л. М., Сапронов В. В., Шершнев Л. И. Безопасность жизнедеятельности. Современный комплекс проблем безопасности: учеб.-метод. пособие для учреждений проф. образования. М.: Русский журнал, 2004. 132 с.

18. ВоробьеВ Ю. Л., ПучкоВ В. А., ДурнеВ Р. А. Основы формирования культуры безопасности жизнедеятельности населения / под общ. ред. Ю. Л. Воробьева. М.: Деловой экспресс, 2006. 316 с.

19. Девисилов В. А. Культура безопасности - важнейший фактор обеспечения устойчивого развития России // Актуальные проблемы формирования культуры безопасности жизнедеятельности населения в современных условиях: материалы XIII Международ. науч.-практич. конф. по проблемам защиты населения и территорий от чрезвычайных ситуаций. Москва, Россия, МЧС России. М.: ИПП «КУНА», 2008. С. 61-69.

20. Михайлов А. А. Формирование компонентов культуры безопасности жизнедеятельности в социуме у студентов педагогического вуза // Научный журнал КубГАУ. 2011. № 68(04). С. 12-14. URL: http://ej.kubagro.ru/2011/04/pdf/29.pdf (дата обращения: 30.06.2019).

21. ГОСТ Р 22.3.07-2014 Безопасность в чрезвычайных ситуациях. Культура безопасности жизнедеятельности. Общие положения // Консорциум «Кодекс». Электронный фонд правовой и нормативно-технической документации. URL: http:// docs.cntd.ru/document/1200109440 (дата обращения: 30.06.2019). 
22. Костенок П. И. Безопасность личности как педагогический феномен // Вестн. Сургутского гос. пед. ун-та. 2018. № 4(55). С. 107-113.

23. Прохожељ А. А. Новые подходы к безопасности в связи с современными концепциями развития // Философия, социология, культурология. 2007. № 1(2). С. 8-12.

24. Литвинов Э. П. Безопасность как философская категория // Пространство и время. 2014. T. 7. Вып. 1. URL: http://www.j-spacetime.com/actual\%20content/t7v1/ t7v1_PDF/2227-9490e-aprovr_e-ast7-1.2014.12.pdf (дата обращения: 30.06.2019).

25. Каверин С. Б. О психологической классификации потребностей // Вопросы психологии. 1987. № 5. С. 121-129.

\section{References}

1. Davydov V. V. (ed.) Rossiyskaya pedagogicheskaya entsiklopediya. In 2 vols. Moscow: Bolshaya rossiyskaya entsiklopediya, 1993. Vol. 1: A-M. 608 p.

2. Polikarpov V.S. Filosofiya bezopasnosti: esse. St. Petersburg - Rostov-on-Don - Taganrog, 2001.

3. Bezopasnost. Terminy MChS. Available at: http://www.mchs.gov.ru/dop/terms/ item/88452/ (accessed: 25.06.2019).

4. Risk. Terminy MChS. Available at: http://www.mchs.gov.ru/dop/terms/item/453796/ (accessed: 25.06.2019).

5. Bek U. Obshchestvo riska: na puti k drugomu modernu. Transl. from German V. Sedelnik, N. Fedorova. Moscow: Progress-Traditsiya, 2000. 383 p. (In Russian)

6. Gubanov V. M., Kapshunova I. K. Filosofskaya interpretatsiya bezopasnosti zhiznedeyatelnosti. Pedagogika vysshey shkoly. 2016, No. 3.1, pp. 62-68. Available at: https://moluch.ru/th/3/archive/43/1446/ (accessed: 25.06.2019).

7. Nesterov S. V. Bezopasnost kak filosofsko-pravovaya kategoriya. Yuridicheskaya nauka. 2013, No. 1, pp. 11-13.

8. Kostenok P. I. Prepodavanie uchebnoy distsipliny "Bezopasnost zhiznedeyatelnosti" v gumanitarnom vuze: realnye dissonansy i potentsialnyy kollaps. Mir nauki, kultury, obrazovaniya. 2016, No. 1(56), pp. 136-145.

9. Efremov S. V., Kovshov S. V., Zinchenko A. V. Noksologiya: ucheb. posobie. St. Petersburg: Izd-vo politekhn. un-ta, 2012. $250 \mathrm{p}$.

10. Klimov O. N. Natsionalnaya bezopasnost Rossii v usloviyakh globalizatsii (politologicheskiy aspekt). PhD dissertation (Politic). Moscow, 2003. $170 \mathrm{p}$.

11. Moiseev N. N. Sudba tsivilizatsii. Put razuma. Moscow: Izd-vo MNPU, 1998. 228 p.

12. Nashe obshchee budushchee: doklad Mezhdunarodnoy komissii po okruzhayushchey srede i razvitiyu (MKOSR). Transl. from English, ed. by S. A. Evteev, R. A. Perelet. Available at: http://устойчивоеразвитие.pф/files/monographs/OurCommonFutureintroduction.pdf (accessed: 29.06.2019). (In Russian)

13. Rybalkin N. N. Priroda bezopasnosti. Vestn. Moskovskogo un-ta. Ser. 7: Filosofiya. 2003, No. 5, pp. 36-52.

14. Sokolova S. N. Fenomenologiya bezopasnosti sovremennogo obshchestva: monogr. Pinsk: PolesGU, 2013. 183 p. 
15. Fetisova Yu. V. Kultura bezopasnosti. Extended abstract of PhD dissertation (Philosophy). Omsk, 2009. 21 p.

16. Gafner V.V. Kultura bezopasnosti: analiticheskiy obzor dissertatsionnykhissledovaniy (pedagogicheskie nauki, 2002 - 2012 gg.). Ekaterinburg, 2013. 200 p.

17. Vlasova L. M., Sapronov V. V., Shershnev L. I. Bezopasnost zhiznedeyatelnosti. Sovremennyy kompleks problem bezopasnosti: ucheb.-metodich. posobie dlya uchrezhdeniy prof. obrazovaniya. Moscow: Russkiy zhurnal, 2004. 132 p.

18. Vorobyev Yu. L., Puchkov V. A., Durnev R. A. Osnovy formirovaniya kultury bezopasnosti zhiznedeyatelnosti naseleniya. Moscow: Delovoy ekspress, 2006. 316 p.

19. Devisilov V. A. Kultura bezopasnosti - vazhneyshiy faktor obespecheniya ustoychivogo razvitiya Rossii. In: Aktualnye problemy formirovaniya kultury bezopasnosti zhiznedeyatelnosti naseleniya v sovremennykh usloviyakh. Proceedings of the XIII International Scientific-practical conference. Moscow, MChS Rossii. Moscow: IPP “KUNA”, 2008. Pp. 61-69.

20. Mikhaylov A. A. Formirovaniekomponentov kultury bezopasnosti zhiznedeyatelnosti v sotsiume u studentov pedagogicheskogo vuza. Nauchnyy zhurnal KubGAU. 2011, No. 68(04), pp. 12-14. Available at: http://ej.kubagro.ru/2011/04/pdf/29.pdf (accessed: 30.06.2019).

21. GOST R 22.3.07-2014 Bezopasnost v chrezvychaynykh situatsiyakh. Kultura bezopasnosti zhiznedeyatelnosti. Obshchie polozheniya. Available at: http://docs. cntd.ru/document/1200109440 (accessed: 30.06.2019).

22. Kostenok P. I. Bezopasnost lichnosti kak pedagogicheskiy fenomen. Vestn. Surgutskogo gos. ped. un-ta. 2018, No. 4(55), pp. 107-113.

23. Prokhozhev A. A. Novye podkhody k bezopasnosti v svyazi s sovremennymi kontseptsiyami razvitiya. Filosofiya, sotsiologiya, kulturologiya. 2007, No. 1(2), pp. 8-12.

24. Litvinov E. P. Bezopasnost kak filosofskaya kategoriya. Prostranstvo i vremya. 2014. Vol. 7, Iss. 1. Available at: http://www.j-spacetime.com/actual\%20content/t7v1/t7v1_ PDF/2227-9490e-aprovr_e-ast7-1.2014.12.pdf (accessed: 30.06.2019).

25. Kaverin S. B. O psikhologicheskoy klassifikatsii potrebnostey. Voprosy psikhologii. 1987, No. 5, pp. 121-129.

Интернет-журнал

«Проблемы современного образования»

2020, № 5

Статья поступила В редакцию 24.02.2020

The article was received on 24.02.2020 